\title{
A Phenomenological Case Study Exploring Different Perspectives on Science Communication through Art
}

\author{
Giedre Straksiene and Zita Rasuole Gasiunaite
}

\author{
"You don't really understand something unless you can \\ explain it to your grandmother" Albert Einstein
}

\begin{abstract}
This article investigates the conceptions of science communication through art. Science communication is a persistent dilemma, with much research conducted on it, yet, limited studies exist on the perception of science communication through art. Both science and art are based on the ability to imagine drawing connection to elucidate complex topics. Is it true whether just romantic idea of collaboration working towards communication? What actually is science communication through art? In what mode or how it is comprehensible to master students and their teachers/scientists? The authors present a phenomenological case study approach based on the focus group data collected from 33 participants including master students and their teachers /scientists of one university of the Lithuania. The data transcribed, thematic concepts and discourse analysis methods used to deconstruct the underlying meanings in verbal and nonverbal forms of communication. Five distinct themes (concepts) emerged: Beauty, Creativity, Education, Sociocultural and Technological. Phenomenological case study disclosed students' and their teachers'/scientists' perspectives on the role of the art in science communication. Science communication through art was perceived as a positive phenomenon which educates society by showing nature beauty as well as using creativity and new technologies. The multi-dimensional aspects of science communication through art need to be fully acknowledged and carefully explored in further research. Hope the findings of this case study have implications for science students' education that should offer opportunities for more consistent art integration.
\end{abstract}

Index Terms-science communication through art, art integration, science students, case study, phenomenological approach.

\section{INTRODUCTION}

The opportunities and challenges are facing to science communication today. A key responsibility of scientists is effectively communicating scientific research to the public [1]. Scientists are supposed to share their research outputs to journalists, politicians, business and general society. Working with complex subject, dealing with partners and sponsors, sorting intellectual property issues and negotiating with powerful publishing houses is challenging. Successful meeting of these challenges are based on the educational system, which in Lithuania, however, faces some systematic problems, related to ineffective science teaching and low

Manuscript received January 29, 2017; revised May 1, 2018.

Giedre Straksiene and Zita Rasuole Gasiunaite are with the Klaipeda University, Herkaus Manto str. 84, Klaipeda, LT-92294, Lithuania (e-mail: giedre.straksiene@ku.lt, zita@apc.ku.lt). academic performance in science [2]. In addition, there remains a pervasive belief among scientists that scientific terms and concepts may be too difficult to communicate to the public [3], [4] and [5]. Therefore, innovators are needed to develop new interdisciplinary forms. Moreover, science communication through art is the growing area of interests of practitioners and researchers. This phenomenon continues to generate extensive debates both at national and international level, as it is reflected in the articles published during the recent years [6], [7] and [8].

A. E. Lesen et al [8] claims, "the arts are becoming a favored medium for conveying science to the public. Tracking trending approaches, such as community-engaged learning, alongside challenges and goals can help establish metrics to achieve more impactful outcomes, and to determine the effectiveness of arts-based science communication for raising awareness or shaping public policy. As a result, the science and art have the potential to develop new approach by being implemented together in cross-disciplinary settings" [9]. Despite this understanding of the role of art in science communication, minimal research currently exists examining the possible relationship between science communication and art, which reflects students' perception about it, thereby enabling them to develop their scientific competence.

In fact, traditional scientific education does not prepared a scientist to be an effective communicator outside the academic space. Speaking generally, the most of the Science faculties in Lithuanian universities do not offer courses, workshops of communication nor in science communication. According to our personal practice, students or young graduates could be strongly inspired to share their knowledge with the society. Therefore, relevant skills, ability to adapt to the different target groups (e.g. schoolchild, wide public, business people etc.) and subsequent successful first experience will motivate them for further activity in science communication. We consider that universities need to pay more attention to training science students of sending scientific message across.

Consequently, one of the most important questions for scientist might be how to convey the scientific results to audience because the society wants to know how new findings might affect their lives. Science students should be prepared to present their research results to audience in suitable, attractive and interesting manner to everybody, because according to J. Gregory [6] science communication is the communication of scientific knowledge and ideas to people who are not scientists. In addition, in science communication, there is no such individual as one "who is not scientist" but rather a number of different "who are not scientists", each with their own level understanding of knowledge, experience 
and esthetics.

The central purpose of this research is to examine views of science communication through art from the perspectives of a number of key master students (ecology and environmental sciences, ichthyology and fisheries, and geoinformatics) and scientists/teachers (natural sciences, humanities and arts). We aimed to answer the following research question in order to understand this phenomenon: How various individuals including master students and scientists/teachers could define the science communication through art? In addition, we tried to discover how the arts could open new pathways to understand and express the scientific knowledge.

\section{BACKGROUND}

Research literature provides evidence that the concept of a science communication is complex, dynamic and influenced by various factors. A range of potentially co-existing, complementary and conflicting discourses about a science communication can be found within the educational, philosophical, psychological and sociological theories and research reviewed.

Generally, science communication is defined as sharing science related topics with non-scientists. For scientists this can take a number of forms: from teaching classes to a radio or TV interview or newspaper article about scientific topic, to a presentation to local high school students. Scientists also consider public outreach and communication integral and beneficial to their scientific research [10], [11].

Looking deeper, T. W. Burns et al [12] defined the science communication as "the use of appropriate skills, media, activities, and dialogue to produce one or more of the following personal responses to science: awareness, enjoyment, interest, opinion-forming, and understanding".

According to M. M. Bakhtin [13], "complexly structured and specialized works of various scientific and artistic genres, in spite of all the ways in which they differ from rejoinders in dialogue, are by nature the same kind of speech communication". At the same time, the individuals from these differing domains are each interacting with their own past traditions.

Humans may perceive aesthetic aspects of scientific phenomena as separate from the actual science, which is the object of scientific study, however there is no such separation.

J. Dewey [14] reminds us, that emotional outbursts of appreciation are not disconnected from the theoretical knowledge, but rather are part of them. "It is possible to enjoy witnessing processes of nature, such as the flowering of plants without commanding theoretical knowledge of those processes. But as one sets out to understand them beyond that initial enjoyment, one must find out something about the interactions of soil, air, water and sunlight that condition the growth of plants."([14], p.2).

Turning back to communication, the key to successful science communication is the use of accessible and relevant language for particular audience. Nonetheless, language is not the only way to communicate, especially talking about science communication. Scientist's communication with audience mostly consists of visual signs such as figures, tables, photos, maps and other conceptual diagrams. J. Bubas [15] states:
"Reality is constructed in language, but language cannot describe reality". Can it be done by art? We can draw a parallel between the scientific information and the relation of art and finding new dimensions of reality and new ways of creation of reality inherent to artistic manner. Furthermore, art is communication intrinsically i.e. non-verbal communication. Additionally, art converts verbal communication (language, words) into non-verbal communication (symbols, images, music, action, movement, dance) when language is not effective. J. Bubas [15] claims "a piece of art can include all manner of subjective information, either formally through manipulation by drama/theatre, music, dance or other forms or elements of art".

If we take T. V. Akhutina's [16] words into account, another reflection of the knowing appears: "Envisioning the scientific story a scientist can lead to comprehensive research program or combining visual elements can lead to new insights and comparing different datasets or approaches can lead to insights. Learning how to communicate science is probably as important a skill as learning how to do science. It is one thing to learn how to collect and analyze data - it is a whole other thing to learn how to effectively communicate science". From this perspective, science communication through art is the creative expression of scientific knowledge that produces works that appeal to the human senses, intellect or emotions. The criteria for science communication through art are twofold: the work has to be considered art, and the artwork had to be within the science realm. An examples could be a photo series/video/ animations depicting effects of climate changes or a music composition reflecting an atmospheric process that affects climate. Using art to help educate and increase awareness of topics and issues has been applied not only for the natural sciences, but also in other scientific fields [17], [18].

From our point of view, science communication should fulfil at least three conditions: to be explicit, comprehensible and attractive. For the scientist, science communication is the best way to test understanding of the subject, since he/she needs to be very deep in, to be able to communicate in comprehensible manner. Using the arts could facilitate to catch the attention of the audience, to stress important points, to raise awareness and to impact everyday habits of the society (e.g. nature conservation, pollution) through the emotional experience of aesthetic.

\section{Methodology}

\section{A. Research Design}

Qualitative research defined as "a situated activity that locates the observer in the world" ([19] p. 3) where researcher aims to understand or interpret a phenomenon in its natural settings through various data sources and collection methods that lead to interpretation [19]. This research adopted a qualitative phenomenological case study approach. The phenomenological approach, fused with the case study method, allows the researchers to understand or make sense of intricate experiences and "the essence and the underlying structure of a phenomenon" ([20], p. 23). The manner, in which individuals comprehend the world around them, is very 
subjective. However, the world is created through relations and objects to which individuals have given specific meaning.

In this approach, researchers have initial knowledge about the topic and are interested in developing a more in depth understanding and clarifying this phenomena [21]. This allowed the researchers to broaden his understanding of the research subject (science communication through art) and go beyond the surface.

\section{B. Participants and Procedure}

This case study involved six focus group interviews and one fact-finding group with teachers/scientists. A total number of 33 participants took part in. Table I (below) show the details of the participants in each of the groups.

TABLE I: FOCUS GROUP PARTICIPANTS

\begin{tabular}{|c|c|c|c|}
\hline Participant groups & Females & Males & Total \\
\hline $\begin{array}{l}\text { Master students / Ecology and } \\
\text { Environmental sciences }\end{array}$ & 11 & 5 & 16 \\
\hline $\begin{array}{l}\text { Master students / Ichthyology and } \\
\text { Fisheries }\end{array}$ & 2 & 3 & 5 \\
\hline Master students / Geoinformatics & 3 & 6 & 9 \\
\hline Scientist / Natural sciences & 1 & - & 1 \\
\hline Scientist / Art & 1 & - & 1 \\
\hline Scientist / Humanities & 1 & - & 1 \\
\hline Total & & & 33 \\
\hline
\end{tabular}

We followed a learning cycle framework to allow master students to explore scientific project/topic in the lectures of Research Methodology including an artist-led lectures aimed to prepare scientific presentation more understandable and attractive for public. This learning principle applied during 2016-2017 (autumn semesters).

During above-mentioned period, master students worked in groups and individually developing science communication material for public. At first, students were asked to prepare written research projects based on the individual topics of their master thesis, then - to discuss these projects in the form of scientific presentation. Science communication through art was the last component of the exercise. Thereby, master students were involved in various stages of learning process, received an unique learning experience and a way to approach and present their research topic through art, for instance, storytelling/music/action/image instead only of scientific data. Subsequently we assessed the learning activity and the communication product using focus group discussions and comments by science, art and communication researchers.

At the end of the learning cycle the research question "How is science communication through art defined by various individuals?" was presented to the focus group and participants were allowed a few minutes to consider quietly. In case the participants were reluctant to engage, the researchers rephrased the question and gave additional explanations to initiate the discussion. The conversations began, the participants interacted with one another, and responses became more spontaneous. The focus group interviews allowed individuals to form opinions about the designated topic and allowed the researcher to witness dynamic, interactive discussion; it also involved exchange of opinions and experience among members of the group [22].
The data were coded and analyzed in two stages. First stage involved a thematic (concept) analysis and second stage used discourse analysis to explore discourses underpinning the issues raised within the focus groups.

\section{Reliability and validity in qualitative data analysis}

The concepts of reliability and validity are of great importance to quantitative research. The reliability and credibility of the research were assessed in two phases. During the thematic and discourse analysis, researchers independently coded the focus group interview transcripts. The detailed coding was discussed through an iterative process until the final themes (concepts) emerged [23].

\section{FINDINGS}

\section{A. Overview of Thematic Concepts}

Regarding to the key research question "How is science communication through art defined by various individuals?" a number of diverse concepts emerged. These are grouped into the five key concepts: Beauty, Creativity, Education, Sociocultural, and Technological - alongside each of the five concepts, comments made by focus group participants are included. The table below (Table II) shows an overview of the variety of concepts generated from all of the focus group discussions.

Looking to the respondents' answers, we can make assumption that science communication through art is not just a human construct aimed to evaluate and collect knowledge about nature (or, in the case of technology, discover new ways of handling nature), but much more. In fact, nature does not depend on human observation in order to exist and develop, as well as to produce educational, sociocultural, and aesthetic outputs which may potentially be perceived by humans. From the other hand, technology (e.g. audio or visual media, computer graphics), which applies the knowledge of science, always has an artistic element in its creation and production, and any activity can be perceived as an art by looking for beauty in the process and results. Nature does not depend on human study, understanding and observation, but human study, understanding and observation turns nature into an object of science.

\section{B. Discourse Analysis of Key Concepts}

This section focuses on the views of both the master students and scientists/teachers groups. Both of the groups discussed a variety of factors concerning their experiences, but not all of their discussions were directly relevant to the main question. The analysis performed using discourse analysis method, taking into account both their linguistic and sociolinguistic discourse within conversation analysis where narratives are seen as interactive accomplishments which may involve co-narration.

TABLE II: SUMMARY OF THEMES OF SCIENCE COMMUNICATION THROUGH ART

\begin{tabular}{ll}
\hline \hline Key Concepts & Examples to illustrate \\
\hline Beauty & "I suppose that scientists promote the message of beauty in \\
& nature in various ways". \\
& "For me it is finding beauty in scientific work." \\
\hline \hline
\end{tabular}




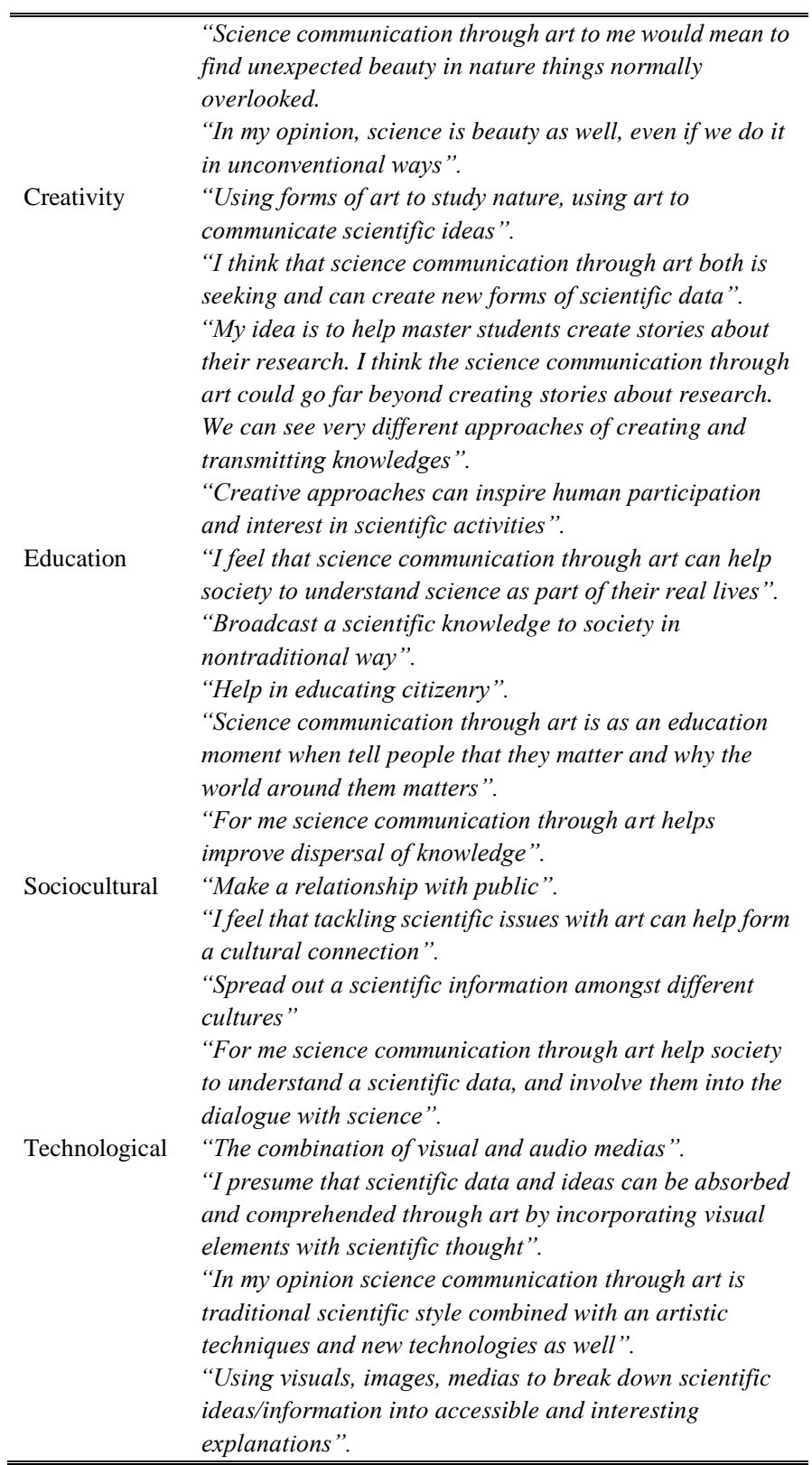

The procedure for a discourse analysis of the data involved several stages, which include the transcription completed for the thematic analysis and the close iterative reading. These are examined how different concepts of science communication through art are disclosed via discourse that allows to identify the meaning aspects much more.

In response to the interviewers' question 'What does science communication through art mean to you?" the focus groups of students and scientists/teachers were quick to formulate varying definitions of this phenomena and these were often accompanied by a positive endorsement.

"By sharing this, scientist is trying to encourage thinking to society and inspire interest in science and nature". $S B$

"Seeking interesting images and forms what can inspire a more diverse variety of viewers to look deeper into the subject". SI

"I suppose that scientists through art reach a wider audience than the individuals could on their own". SI

A few participants spoke that art also has the ability to create emotional connections between its subject and the public and empower communities by fostering their consciousness. Transferring experiences emotionally connects the public to the environment, which is crucial for public awareness.

"Focusing on engaging audiences on an emotional level and establishing a cultural and environmental awareness". $S G$

"For me science communication through art helps improve dispersal of knowledge. It also increases participation of a wider audience". SE

"I believe that promoting science communication through art is a great way to expand access and understanding to society about science. It has become easier to share information, and doing it in an interesting". TS

All these sentences illustrate the positive emotions the students felt throughout their experience and variables as well as the contexts that caused their range of emotions.

The scientific journey through art of students' teacher experiences can be captured in the following reflection, and it reads as follows:

"I had my first project of science communication more than 20 years ago, together with the team of young university graduates of natural sciences. There was a voluntary action, without any financial support, driven only by inspiration and intrinsic desire to show the magic of science. We started from the short TV shows, illustrating different phenomena of the everyday life, however, shortly come to the conceptual misunderstanding with the producers, giving the preference to the doubtful esoteric topics instead of scientific knowledge.

Soon after the TV experience, we continued with the series of popular articles and gradually our enthusiasm has cooled off. Several years later I was awaked by professor Ilppo Vuorinen from Archipelago Research Institute (Turku University). In the speech at the conference for young scientists he talked about the importance of ability to communicate scientific knowledge in comprehensible way and his sentence "can I tell Mama?" written on the large sheet of paper become one of the most important and stimulating posters at the room of PhD students." TS

Throughout focus group interviews, the aspects of creativeness were generally discussed more than other views on science communication through art.

"I'm a scientist, not an artist. For me, artists are synonymous with creativity." $S G$

"I think scientists lack the passion and spirit that artists possess" SE

In particular, the students were focused on the importance of creative elements, artistic knowledges and abilities. In this study's case, we also indicated the challenge to communicate with audience, because the students are focused on fundamental knowledge and feel a lack of artistic abilities and self-confidence to communicate in creative way since their experience in this field is very limited as illustrated by their quotes:

"Ï do not know nothing about artistic activities. How to express my idea, my topic using art?" $S E$

"I am lacking of knowledge about art" SI

"I have never worked with artists" SE

This confirms that a high source of stress is, indeed, directly related to the absence of the science students' personal artistic experience. Also these findings indicate that 
without prior training in the arts, a person is not likely to partake in the science trough art movement. This idea is supported by many psychological theories that state that familiarity of a subject will increase a person's tendency to perform it [24], [25].

Even the scientist confronts this problem, especially at the stage of early career, due to the lack of practice of science communication. This aspect can possibly be explained by the fact that scientist may consult with artist for guidance, for instance, scientist states:

"Looking retrospectively, I realised a continuous need of integration of art and science throughout my scientific career It was not a problem for me and my colleagues, since for many years we have a professional artist in our team, able to provide us nice drawings, web design solutions etc. We are asking her to prepare the design for the materials of conferences and projects, to help with complicated drawings for our articles" TS

Again, students and their teachers understand the aspect of creativity in science communication, and for this reason they need a contact with artists. This reflection directly ties to the students and their teachers feelings about working with artists.

"For that reason, we need partnerships with artists. We hope that these partnerships will also spark new ideas in both art and science, leading to innovations and solutions to the problems faces today. However, little is known about art integration practices in everyday science teaching ". TS

"For example, artistic approach and abilities were necessary when we were writing a methodical book - to prepare attractive cover, schemes, graphs and original drawings of biological species. Similar story was with an educational film for students: after the preparation of the scenario and basic visual material we understood that an artistic part-animation and music - is equally important for the good result". TS "I think there are some points in which scientists and artists might overlap in collaborative activity: the idea, the process, and the result". SE

Moreover, it is important, that students notice the differences between science and art in analyzing the object. This means that artist express knowledge in the form of subjective and very personal perceiving, while scientist goes by objective way and presents the proved knowledge. One university student said in her interview:

"The science has created an intricate system of validating knowledge, talking about artists' activity I presume that the output not necessarily be validated $<\ldots>$ scientists are rigid and analytical". SG

Throughout the focus group interviews, it was apparent that the teachers often made implicit references to the multiple aspects of science communication through art. In particular, they emphasized the importance of adopting a holistic viewpoint in science communication through art. In the quote below, the teacher openly expresses the experiences and emotions she endured throughout her teaching semester:

„, The presentations made by science students are a small step on science communication journey. There are findings you cannot express with words, and that is where non-verbal communication comes in. The medium is art. Verbal language is an inefficient, incomplete form of communication that is prone to misunderstandings. Completing it by the sensual, emotional, and intuitive spheres will provide a more holistic form of science communication through art ". TA

It was revealed, that scientists have their own individual personalities and individual reactions to the situations from the different perspectives. Each representative of the natural sciences encounters a variety and beauty of shapes and colors of life following by the fascination with the laws of nature. Not surprisingly, many scientists are dedicated artists, able to present their study objects by, e.g., fine arts or photography. The practice in arts, in turn, facilitates deeper knowledge of the scientific object and creativity in academic field.

"After nearly twenty years of common work with an artist in the team I could conclude that this is an excellent solution for the scientists and challenging experience for the artist, because he/she should learn scientific language, to understand the research object, scientific topics and relevance". TS

Again, looking from an artistic perspective, communication with science starts with intuition and symbols culled from a variety of sources of nature.

"Some years ago, I saw photo exhibition of birds, and I have been naturally asked myself, what is the idea of the author who is scientist, and how does the exhibition communicate with viewers who are not scientists? It was my first connection with nature science, and I think there is some science in the art, and some art in the science". TA

In order to increase the credibility of this study, peer debriefing was applied. We implemented peer debriefing with another colleague in the other university in which the selected program is hosted. We provided an overview of the study included the purpose of the study, the research question, data analysis, findings, and implications. In our conversation, we encouraged her to ask questions, provide feedback, and offer suggestions regarding any additional ideas they may have had. Her thoughts mirrored many of ours and she indicated that this study was important to the work we do and for future research.

\section{FINAL REMARKS AND IMPLICATION}

The objective of this study was to describe views of science communication through art from the perspectives of science master students and their teachers/ scientists. Also, to extract key themes (concepts) through coding and discourse analysis, and create a preliminary picture of the science communication through art. Based on the five concepts generated, the definitions of science communication through art support the previous research literature as evidence that science and art communication is a multidimensional, complex and dynamic concept.

This research explored different perspectives in regarding to the different individuals (master students and scientists/teachers). Such multilevel perspectives facilitated the gathering of evidence about the wider holistic contexts and the creative thinking of science.

Furthermore, incorporating arts into scientific activity helped to engage multiple senses and emphasized social interaction, as well as supported students to think creatively. The art helped to encourage peer learning and normalize 
different views among students in communicating about their scientific topic/project impacts. Students developed effective communication products based on scientific knowledge and creativeness. It should also be noted that integrating art into science education could engage students with creative projects and encourage students to express science in multitude of ways.

We concluded, that, in order to strengthen science for the benefit of society, scientists need to be responsive to the changing needs and concerns of society. Whereas the art could facilitate society to understand and support the positive role of science. Art has been a means of communicating science, however, this movement of using art to communicate science has yet to be examined on a large scale. There is ample opportunity to continue studying the interface between science communication through art.

\section{REFERENCES}

[1] S. E. Brownell, J. V. Price, and L. Steinman, "Science communication to the general public: Why we need to teach undergraduate and graduate students this skill as part of their formal scientific training," Journal of Undergraduate Neuroscience Education, vol. 12, E6-E10, 2013.

[2] Lietuvos švietimo būklès 2013-2016 m. apžvalga. [Online]. Available: (see online access file:///D:/Downloads/Lietuvos\%20\%C5\%A1vietimo\%20b\%C5\%ABk $1 \% \mathrm{C} 4 \% 97 \mathrm{~s} \% 2020132016 \% 20$ metais\%20ap\%C5\%BEvalga_suredag uota_skelbimui.pdf

[3] P. M. Groffman et al., "Restarting the conversation: challenges at the interface between ecology and society," Frontiers in Ecology and the Environment, vol. 8, pp. 284-291, 2010.

[4] M. L. Pace et al., "Communicating with the public: opportunities and rewards for individual ecologists," Frontiers in Ecology and the Environment, vol. 8, pp. 292-298, 2010.

[5] M. Leggett and M. Finlay, "Science, story, and image: A new approach to crossing the communication barrier posed by scientific jargon," Public Understanding of Science, vol. 10, pp. 157-171, 2001.

[6] J. Gregory. (2015). [Online]. Available: https://www.sciencedirect.com/science/article/pii/B97800809708689 50888)

[7] M. S. Jucan and C. N. Jucan. (2014). [Online]. Available: https://www.sciencedirect.com/science/article/pii/S18770428140500 10

[8] A. E. Lesen et al., (2016). [Online]. Available: https://www.sciencedirect.com/science/article/pii/S01695347163007 38

[9] G. Straksiene, A. Batuchina, and B. Horin, "Science and art: A phenomenological approach to developing a dialogue in the educational context in international conference proceedings," The Future of Education, 2017.

[10] R. W. Abrams. Why we should ELP people understand our scientific literature. Conservation Biology. [Online]. Available: http://onlinelibrary.wiley.com/doi/10.1111/cobi.12543/full

[11] S. R. Davies, "Constructing communication: Talking to scientists about talking to the public," Science Communication, vol. 29, pp. 413-434, 2008.
[12] T. W. Burns, D. J. O'Çonnor, and S. M. Stocklmeyer, "Science Communication: A Contemporary Definition," Public Understanding of Science 2003, vol. 12, p. 183, 2003.

[13] M. M. Bakhtin, Speech Genres and Other Late Essays, University of Texas Press, Austin, 1986.

[14] J. Dewey, Art as experience. (2005). [Online]. Available: https://books.google.lt/books?id=aAbqAGo5MwwC\&printsec=frontc over\&hl=lt\&source=gbs_ge_summary_r\&cad=0\#v=onepage\&q $\& \mathrm{f}=\mathrm{fa}$ lse

[15] J. Bubas, Between Art and Science. [Online]. Available: http://www.oris.hr/files/pdf/zastita/112/Oris.87_Invisible.Structures.p df

[16] T. V. Akhutina, "The theory of verbal communication in the works of M. M. bakhtin and L. S. vygotsky," Journal of Russian and East European Psychology. vol. 41, no. 3, 96-114. 2003.

[17] S. Ede, Art and Science, 2012.

[18] R. Klanten, and P. Alonso, "P. Art \& agenda: political art and activism," 2011.

[19] N. K. Denzin and Y. S. Lincoln, "Introduction: The discipline and practice of qualitative research," Thousand Oaks, CA: Sage Publications. 2011.

[20] S. B. Merriam, Qualitative Research: A Guide to Design and Implementation, San Francisco, CA: Jossey-Bass. 2009.

[21] M. Denscombe, The Good Research Guide for Small Scale Social Research Projects, (2nd Edn) Berkshire: Open University Press. 2004.

[22] D. L. Morgan and M. T. Spanish, "A new tool for qualitative research," Qualitative Sociology, vol. 7, no. 3, pp. 253-270, 1984.

[23] M. Q. Patton, Qualitative Evaluation and Research Methods (3rd Edn), CA: Sage Publications, 2002.

[24] N. Schwarz et al., "Ease of retrieval as information: Another look at the availability heuristic," Journal of Personality and Social Psychology vol. $61,195,1991$

[25] R. B. Zajonc, "Mere exposure: A gateway to the subliminal," Current Directions in Psychological Science, vol. 10, pp. 224-228, 2001.

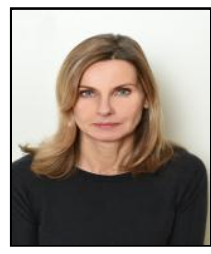

Giedrè Strakšienè was born in Vilnius, Lithuania, in 1966. She received her master in tetralogy at Klaipeda University, Faculty of Humanities Sciences of Klaipeda University, Lithuania, 2001. The PhD in social sciences at Klaipeda University, Klaipeda, Lithuania, 2013. Currently she is research scientist of the Centre of Study of Social Changes at Klaipeda University, Lithuania. Her research interest focuses on development of communicative competence, science and art communication, development of communication through drama activites

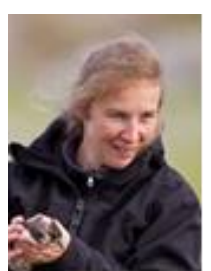

Zita Rasuolė Gasiūnaitė was bron in Pasvalys, Lithuania, in 1970. She received her master in biology (ecology) at Vilnius University, Faculty of Natural Sciences, Vilnius, Lithuania, 1993. She received her $\mathrm{PhD}$ in biomedical sciences at Klaipeda University and Institute of Ecology of Vilnius University, Klaipèda, Lithuania, 2000

Currently she is lead scientist and director of the Marine Research Institute of Klaipeda University, Lithuania. Research interests include aquatic ecology with the focus on transitional ecosystems, ecology of coastal zone, aquatic food webs, plankton ecology, pelagic food webs. 